\title{
Botox and Fillers, are they Cosmetic or Therapeutic?
}

\author{
${ }^{1}$ Faculty, Periodontic Department, KSU, Riyadh, Saudi Arabia \\ ${ }^{2}$ Medical Interns, KSU, Riyadh, Saudi Arabia \\ ${ }^{3}$ Dental Resident, KSU, Riyadh, Saudi Arabia
}

Razan Alaqeely ${ }^{1}$, Elham Alzahrani ${ }^{2 *}$, Alhanouf Aljaloud ${ }^{2}$, Shatha Alzahrani ${ }^{3}$

\begin{abstract}
DOI: $10.36348 /$ sjodr.2021.v06i01.001
| Received: 20.12.2020 | Accepted: 30.12.2020 | Published: 05.01.2021

*Corresponding author: Elham Alzahrani

Abstract

Majority of the population has become obsessed to find a magical lantern for an enduring youth and health and searching for ways to restore it using Botox and Fillers. Their perspective view directed toward the cosmetic aspect of dermal fillers and Botox with ignorance to the primary purpose of inventing such materials which is the therapeutic properties. A qualitative review of the literature is conducted to addresses a gap in the literature regarding both Botox and Fillers to record their types, mechanism of action, uses, Complication and side effects.
\end{abstract}

Keywords: Botox and Fillers, Therapeutic, side effects.

Copyright ( 2021 The Author(s): This is an open-access article distributed under the terms of the Creative Commons Attribution 4.0 International License (CC BY-NC 4.0) which permits unrestricted use, distribution, and reproduction in any medium for non-commercial use provided the original author and source are credited.

\section{INTRODUCTION}

With aging, soft tissue cells start to lose its volume as a natural consequence of aging process. The degree of aging entertains different ratios among different people, as well as different anatomical sites even within the same individual [1]. Cutaneous aging has two parallel series of actions that progressively play a role to achieve alterations as loss of structural integrity and physiological function of aged skin [2]. These two determinants are categorized as intrinsic and extrinsic each of which has it is own effect. The intrinsic aging process is inevitably happening in response to the physiological changes under the influences of genetic control [3, 4]. It involves: the effects of gravity, sleep and expression lines, hormonal changes besides atrophy [4]. Contrarily, extrinsic process possesses the impact of environmental factors that accumulate to produce overtime its effect [4]. These factors include exposure to both ultraviolet and chemical components. Containing exposure to sunlight, pollution or nicotine, repetitive muscle actions like squinting or frowning, and miscellaneous lifestyle components such as diet, sleeping position and overall health [1]. Majority of population has become obsessed to find a magical lantern for an enduring youth and health. They are looking for the ability to restore young appearance and recapture their youthful features [5].
Their perspective view directed toward the cosmetic aspect of dermal fillers and Botox with ignorance to the primary purpose of inventing such materials which is the therapeutic properties.

\section{Botox \\ Definition}

BOTOX is taken from a bacteria known as Clostridium botulinum bacterium in which this microbe produces a protein and neurotoxin necessary for the formation of this material and it was discovered by Emaile van in 1897 [6].

Since then, BOTOX has been experimented for therapeutic uses and approved for certain medical treatment tell 2002 where Food and drug administration (FDA) has approved the use of Botox for cosmetic and therapeutic application [6].

\section{Types and Mechanism of Action}

Currently, there are seven recognized serotypes of botulinum neurotoxin which is $(\mathrm{A}, \mathrm{B}, \mathrm{C} 1$, D, E, F and G) [7]. For commercially use, (Botox, Dysport and Xeomin) (Fig-1) are the only three forms of type A that are available and one type of B which is (MyoBloc) (Fig-2). 

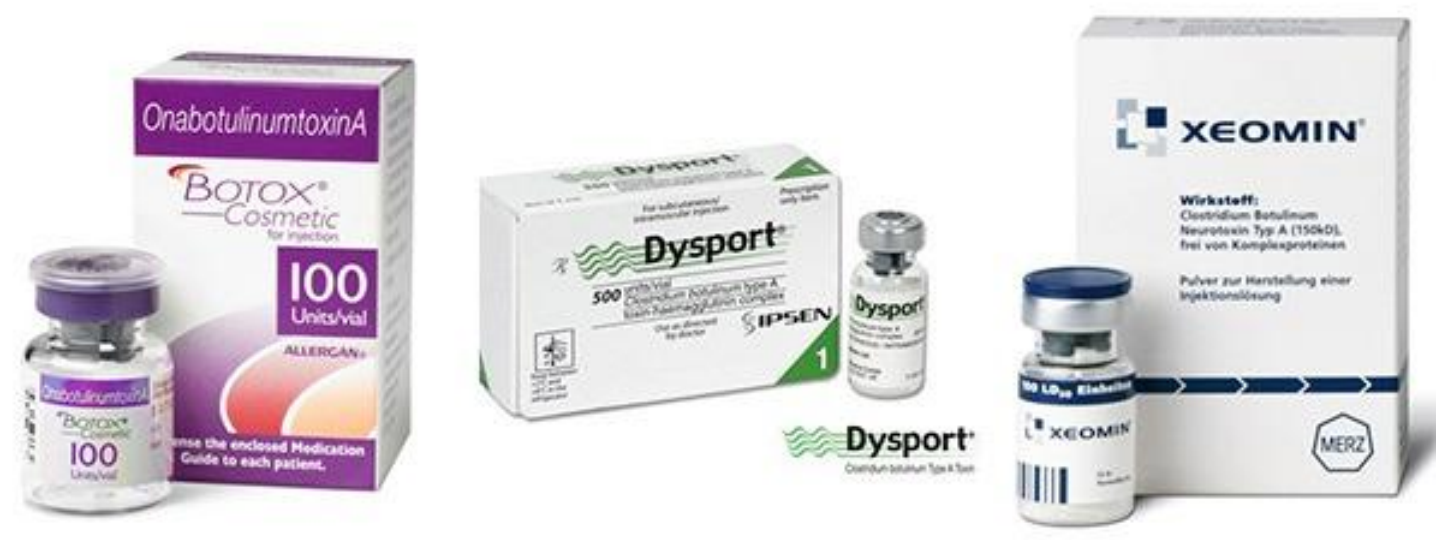

Fig-1: Type A botulinum neurotoxin (Botox, Dysport and Xeomin)

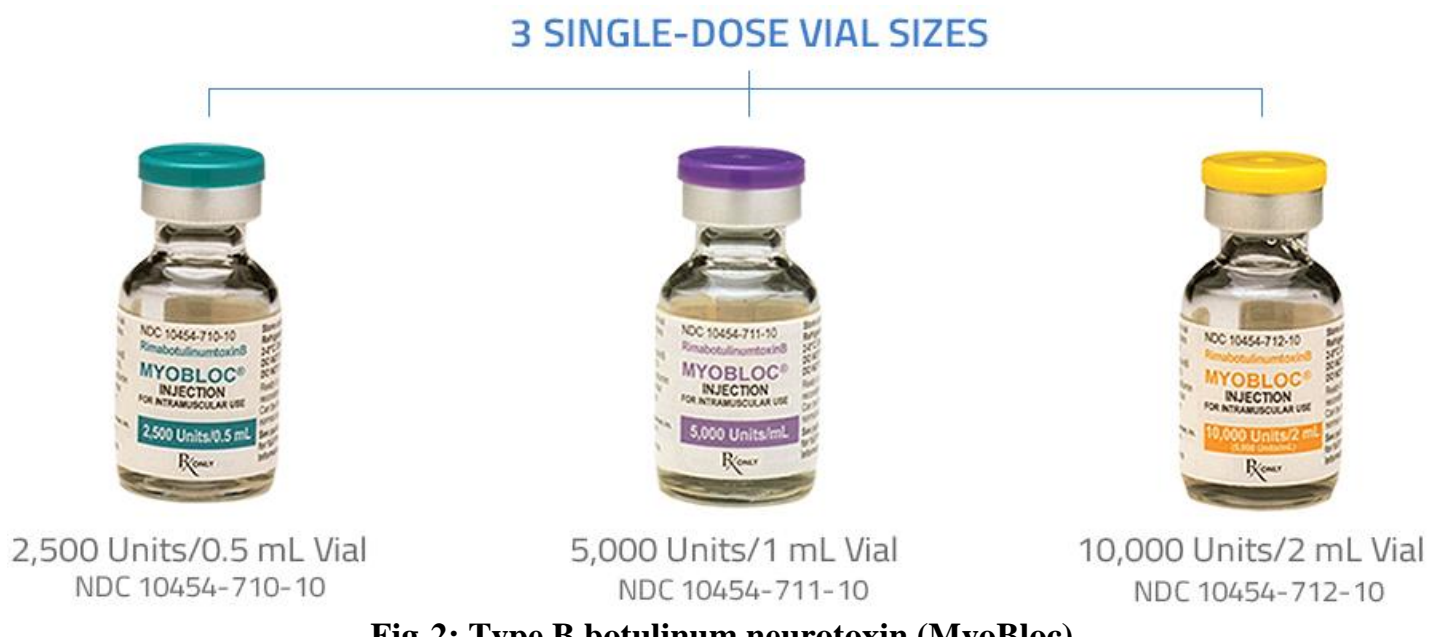

Fig-2: Type B botulinum neurotoxin (MyoBloc)

Type A Botulinum toxin works by inhibiting the release of acetylcholine on cholinergic nerve endings (neuromuscular junction) of motor nerves thus resulting in flaccid paralysis of the overactive muscle [8].

\section{Botox Background}

In early 1970s, the concept of clinical implantation of such material is owned to Dr. Alan Scott while he was investigating a non-surgical replacement for treatment of strabismus where it was experimental on animals only. The first application on human was in 1977. Since 1989, FDA has approved BOTOX® (previously known as Oculinum $®$ ) for the treatment of blepharospasm (involuntary spasm of the eyelids) and strabismus (crossed eyes or wall eyes) [9].

Strabismus is a group of disorders such as crossed eyes in which eye position deviates from the normal midline. On the other hand, regarding cosmetic part it took part in mid 1980s. His experience emphasized his successors to begin the use of Botulinum A Exotoxin for treatment [9].
Botulinum Exotoxin type $\mathrm{A}$ is considered one of the most powerful molecules in the world because of it is significant capability of affecting nerve cell function in unthinkably little quantities [10].

Further after FDA approval of cosmetic use of A type for facial wrinkles 'Glabellar line' people has become conversant with Botulinum Exotoxin A (BOTOX®, Allergan, Inc.) [11].

Furthermore, at 1990 BOTOX® was treatment of choice for cervical dystonia, the FDA officially approval of BOTOX $®$ for such indication took place at 2000. Cervical dystonia is a neurological syndrome characterized by painful involuntary, repetitive or constant contractions of the neck muscles that causes abnormal postures [12].

In 1993, a technique known as laser resurfacing was combined with Botulinum A Exotoxin and such combination permitted the opportunity for adjunctive use of botulinum A exotoxin with other different cosmetic procedures especially those including 
the upper face as endoscopic brow lift, upper and lower eyelid blepharoplasty (involuntary spasm of the eyelids), and in the lower face to enhance the aesthetic effects of face lifting procedures [9].

In addition to its on-label uses, BOTOX® has been used off label in spastic disorders associated with cerebral palsy, stroke, spinal cord injury, closed head injury, and multiple sclerosis. Additionally, BOTOX® has been used off label in the treatment of primary headache disorders such as migraine and chronic pain syndromes involving the back and shoulders [13].

The bacteria responsible to produce both the protein and the neurotoxin essential for construction of this material is known as bacterium Clostridium botulinum. The types that are known of $\mathrm{C}$ botulinum are eight immunologically distinctive types, but only types A, B, and E have been connected to human botulism [12].

Uses

Botox takes part in dental practice and the use of this material has been significantly increased nowadays as it plays role in therapeutic treatment of certain oral conditions. Since July 26, 2013, general dentists' ability has been affirmed to use Botox and dermal fillers for functional or aesthetic dental conditions by the Dental Quality Assurance Commission (DQAC) of Washington.

Botulinum toxin type A can be used in several dental conditions are either associated with musculature or dental compartments as Temporomandibular joint disorders, Mandibular spasm, Masseteric hypertrophy, Bruxism, Pathologic clenching, Oro-mandibular dystonia, Pathologic clenching, Dental implant and surgery and Gummy smile (Fig-3) [11].

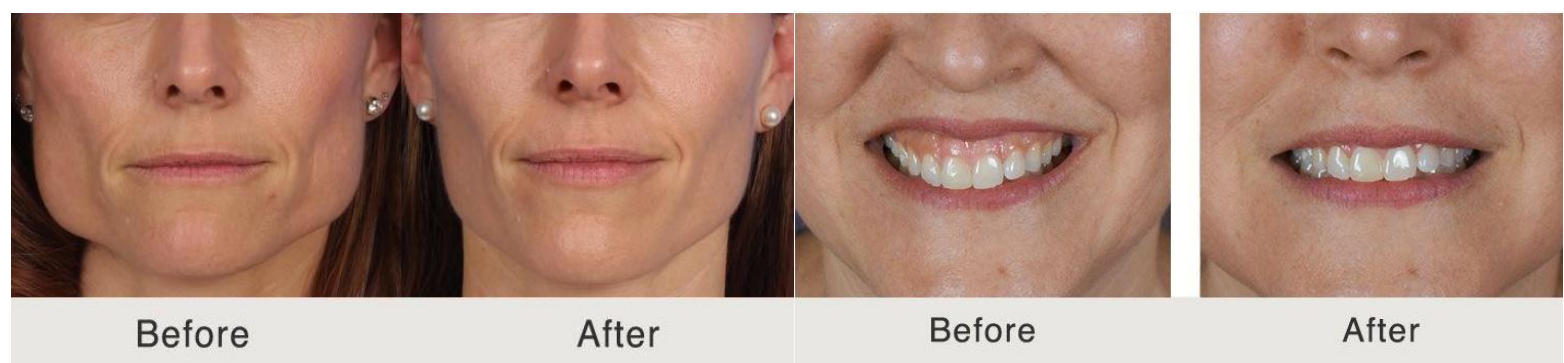

Fig-3: Some of the use of Botulinum toxin type A in treatment of Gummy smile (right), Masseteric hypertrophy (left)

\section{Complication and Side Effects}

As with any invasive or non-invasive surgical procedure, injections are not without any risks. Botox in high concentration or in repetitive injections with short period in between will eventually result in paralysis as Botulinum toxin acts by interfering between nerves and muscles connections [7]. Therefore to minimize the unwanted event a correct injection technique is needed.

Nevertheless, it is generally a highly safe treatment for most patient with few complications when administered correctly $[14,15]$.

\section{Side Effect Include}

Reported contraindications for BOTOX include the use of (quinine, calcium channel blockers, penicillamine, or aminoglycoside antibiotics). BOTOX is also a relative contraindication for patient with neuromuscular diseases and it's a C category for pregnant women which include: women who are attempting pregnancy, pregnant or lactating women [16-18]. The physician should also be aware of the patient allergic reaction to any of the BOTOX component[19].

The ten main errors when injecting BOTOX are [20]:

1. Using an excessive amount of BOTOX will lead to lack of expression, some would advise using less amount than the recommended dose in the articles and textbooks for more natural appearance. However, patients should be informed that the effect will last for a shorter period of time than the usual (Fig-4).

2. Mephisto effect or 'devil eyebrow' which result of injecting the Frontalis Muscle Instead of the Corrugator Supercilii Muscle and that will lead to a relaxation in the middle portion of the eyebrows and compensatory contraction on the lateral side (Fig-4).

3. Excessively elevated eyebrows due to the injecting of botulinum toxin into the superior lateral portion of the orbicularis oculi muscle leading to relaxation of the fibers and in result the eyebrows will be lifted.

4. Eyebrow and/or eyelid Ptosis resulting from injection of the BOTOX into the frontalis muscle with patient who use it to lift their eyelids and it is usually observed with elderly patient how are 65 years or older (Fig-5).

5. Exacerbation of undereye bags happens with patient because of herniated fat or fluid retention have undereye bags and are injected with botulinum toxin in the most inferior portion of the orbicularis oculi muscle. 
Razan Alaqeely et al; Saudi J Oral Dent Res, Jan, 2021; 6(1): 1-8

6. Failure to include the lower third of the face when injecting BOTOX will result in less efficient overall result.

7. Unnatural wrinkles happens when BOTOX is injected into the desirable muscle and the adjacent muscle compensate by contraction, in some cases that leads to new unwanted telltale wrinkles. 'Bunny lines' are one of the classic wrinkles that are caused by botulinum toxin injection (Fig-5).
8. Lack of understanding of muscle contraction patterns for each individual patient will result in an unnatural appearance.

9. Masculinization of women's appearance by injecting the wrong area will give more straight and sharp future and it also can feminize a men's appearance by the same way.

10. Suboptimal result could happen if the case needs a combination of BOTOX and other cosmetic treatments as the case of lost facial fat volume.

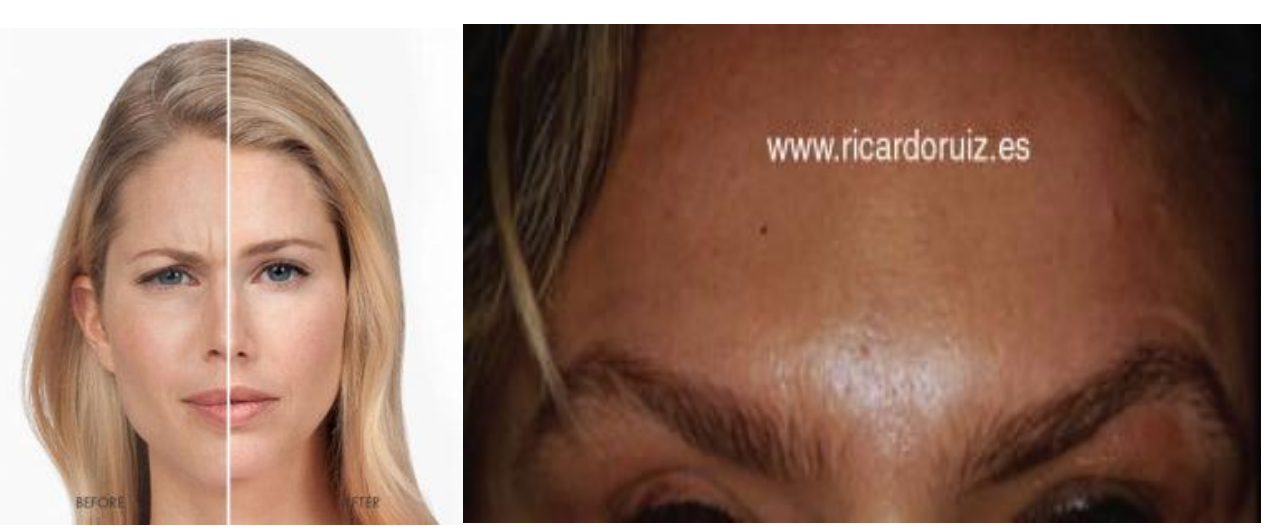

Fig-4: Lack of expression due to using an excessive amount of BOTOX (right), Mephisto effect or 'devil eyebrow' as a result of injecting the Frontalis Muscle (left)

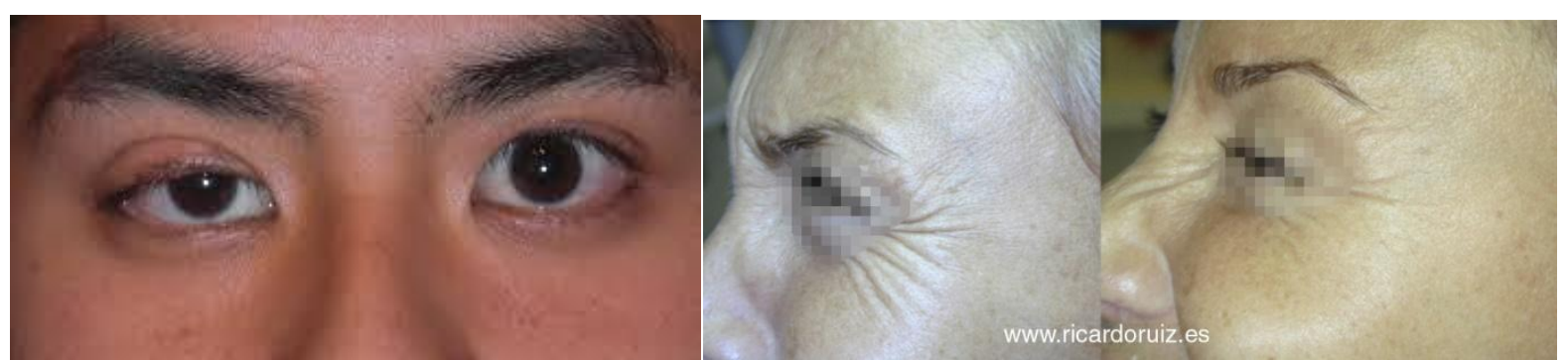

Fig-5: Eyelid Ptosis due to injection of the frontalis muscle (right), telltale wrinkles 'Bunny lines' as a result of compensation (left)

Fillers

\section{Definition and Background}

Human being keened on inventing techniques and tools that would serve in improving their appearance throughout history such as facial painting, wearing different shapes of jewelry, piercings, and do tattooing. This passion drove them to think of creating a perfect material to fill off wrinkles lines of face and replace volume.

Derma fillers are materials that are injected beneath the skin it contains ingredients that add fullness to areas that have thinned due to aging. it also add volume, smoothing out perioral folds and area of reduced volume [21].

Injectable dermal fillers should ideally pose the following properties: biocompatibility; safety; stability at the implant site; and the ability to maintain their volume, remain pliable, induce minimal foreign body reactions and not cause foreign body granuloma
[22].

\section{Types and mechanism of action}

There are four major categories that it falls in (autologous implants, collagens, HAs and biosynthetic polymers).

In 1893, the first category was introduced by Neuber's for soft-tissue augmentation. However, due to the limitation in the reproducibility of the effect and the Immunologic concerns the use of this type of filler has declined until the late 1970s. Nevertheless, after improving lipectomy suction and harvesting techniques the autologous fat graft has increased in demand in the market [23, 24].

Collagen in injectable form has a variable concentration of purified bovine or human collagen and before the introduction of Hyaluronic Acid fillers [24], it was the 'gold standard' injectable filler. One of its advantages over the lateral is that it is less viscous and 
less likely to produce irregularities for treatment and correction of fine lines and wrinkles [25]

Hyaluronic Acid is naturally present in the extracellular matrix of the body where it offers a framework for collagen development. HA is a polysaccharide with hydrophilic properties, so it has a high affinity for binding with water molecules[26]. So, it is main function involve lubrication, hydration and maintaining the equilibrium of connective tissue [26]. Due to their hydrophilic properties, it can attain considerable soft tissue augmentation and when a suitable amount of volume is injected it cannot be distinguished either visually or by palpation. Compared to collagen fillers, Hyaluronic Acid can last up to 6-9 months or longer depending on the type used. whereas collagen fillers can only remain for a few weeks or months [25].

Synthetic fillers are generally composed of one of the biosynthetic polymers such as (e.g., poly-L-lactic acid, calcium hydroxyapatite and polymethylmethacralate) that are joint with injectable carriers [24, 27, 28]. Synthetic polymers are preferred over the other types of filler due to their ability for more permanent results which earned them popularity among plastic surgeons. However, that would also raise the concern over the high rate of long term adverse effects or unwanted events [29].

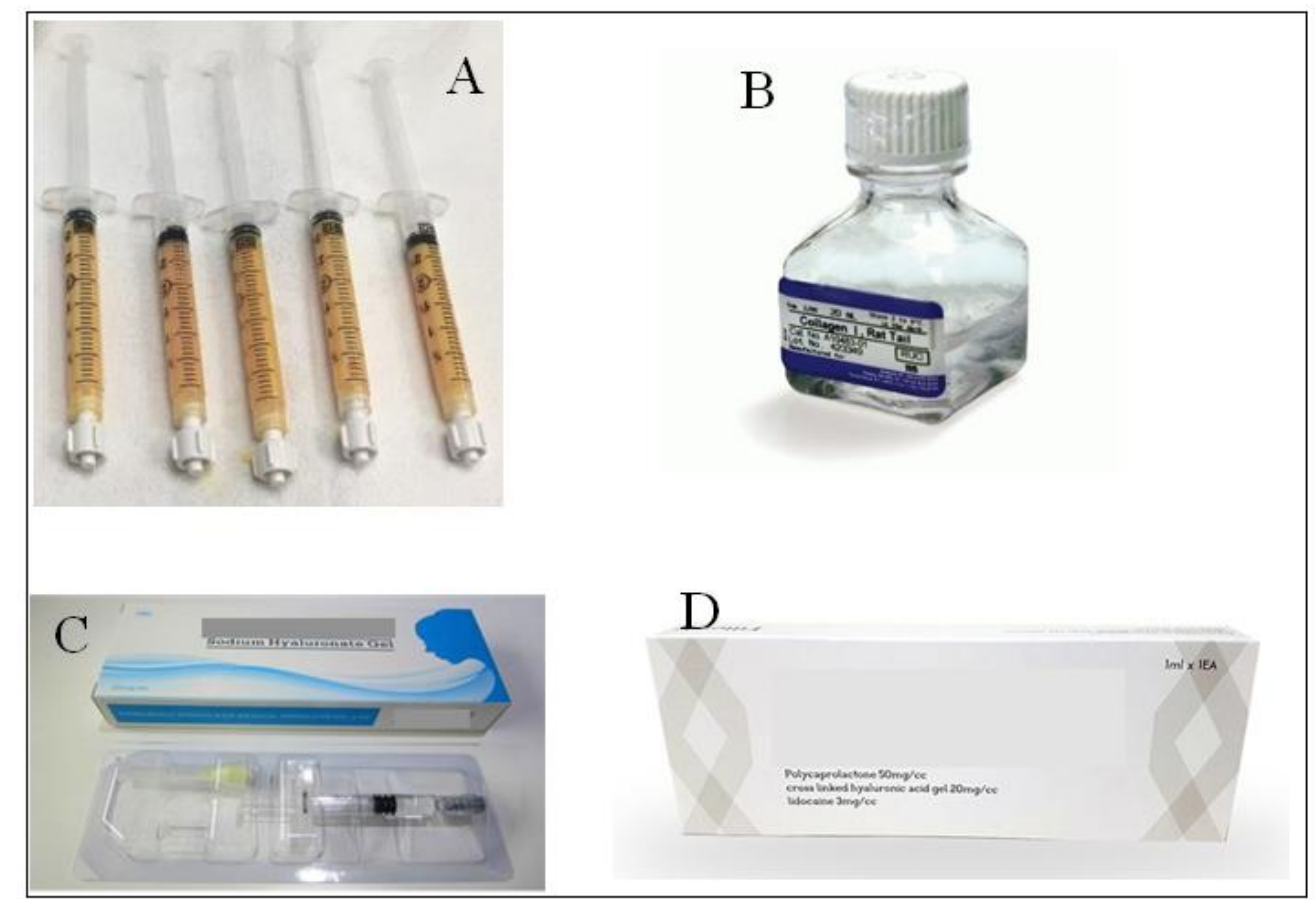

Fig-6: Types of fillers: autologous implants (A), collagens (B), HAs (C) and biosynthetic polymers (D)

\section{Paraffin}

Throughout decades several materials have been discovered and used, first injectable filling was paraffin, the story for using this material started 1830 when Baron Karl Ludwig von Reichenbach a German Chemist noticed an unreactive substance formed by the dry distillation of beech-wood tar [30]. Following that the material has been used by different specialties:

- Lubricating resected joints between (18251899)

- $\quad$ Cosmetic purposes (1844-1924)

- As a petrolatum, a mixture of solid and liquid paraffin, with commercial name Vaseline (1875)

- Nasal augmentations

But after numerical complications were associated with paraffin, it was abandoned. These complications include: migration, embolization, and granuloma and scar formation [30].

\section{Autologous Fat}

For facial augmentation during late 1800s, autologous fats were used either by harvesting from an else body part in 1893 or by using the Illouz method (high vacuum suction with blunt cannulas) in 1982 [30].

\section{Silicon}

The ship of Cosmetic treatment in 1960s was led by liquid silicone injection. Silicone does not share only physical characteristics with Paraffin which are Inerrability, clarity, oily substance but also its complications that mentioned previously. The uses of this material included: breast augmentation, facial wrinkles and augment the lips, but due to the obvious side effects FDA and the American Medical Association had banned their use for cosmetic aspect in 
1979. While there is available medical-grade silicone for ophthalmic use in the treatment of detached retinas, the cosmetic use was prohibited is some states. Despite the statements advised to avoid Silicone in cosmetic use, some countries persist on consumption of Silicone [30].

\section{Collagen}

Bovine collagen is formed by a closed herd of cattle to prevent the transmission of bovine encephalopathy virus. To minimize age-related wrinkles several clinical trials for 6 years on bovine collagen were done. It was first agent approved by FDA for cosmetic reasons in 1981. As sensitivity from such material is possible, pre-testing for allergy must be performed prior to facial injection [30].

History of first facial filler to be accepted for cosmetic practice made by Zyderm in 1981. This was shortly followed by the FDA approval of Zyderm II and Zyplast (Allergan, Inc., Irvine, CA) in 1985 [30].

\section{Hyaluronic Acid}

The need for biocompatible substance that will survive longer than collagen lead to the creation of Hyaluronic acid (HA). It is a highly hydrophilic glycosaminoglycan that is segment of the extracellular matrix of a large variety of tissues in all organisms. The combination of following advantages had made the material to be the most widely used filler nowadays. Advantages include safety, reliability, and a relatively long duration of action [30].

Manufacturing to from HA has two techniques: bacterial fermentation and extraction from rooster combs. The animal derived fillers (Hylaform [INAMED Corporation, Santa Barbara, CA]) in comparison to bacterial-fermented partner (Restylane [Medicis Aesthetics, Inc., Scottsdale, AZ] Juve'derm [Allergan, Inc., Irvine, CA] Captique [Genzyme, Ridgefield, NJ] Elevess [Anika Therapeutics, Woburn, MA]), it afforded excellent cosmetic outcomes but on the other hand it showed shorter duration [30].

In 2003 FDA approved the cosmetic use of $\mathrm{HA}$, which was the gate for inventions new fillings agents between 2003 to 2007. Those approved by FDA in the past 5 years [30].

Utilization of these agents was restricted to nasolabial folds. Augmentation in other regions of face was considered "off-label ". Adverse effects associated were swelling, inflammation, erythema, allergic reaction, infection, vascular events, and pain [30].
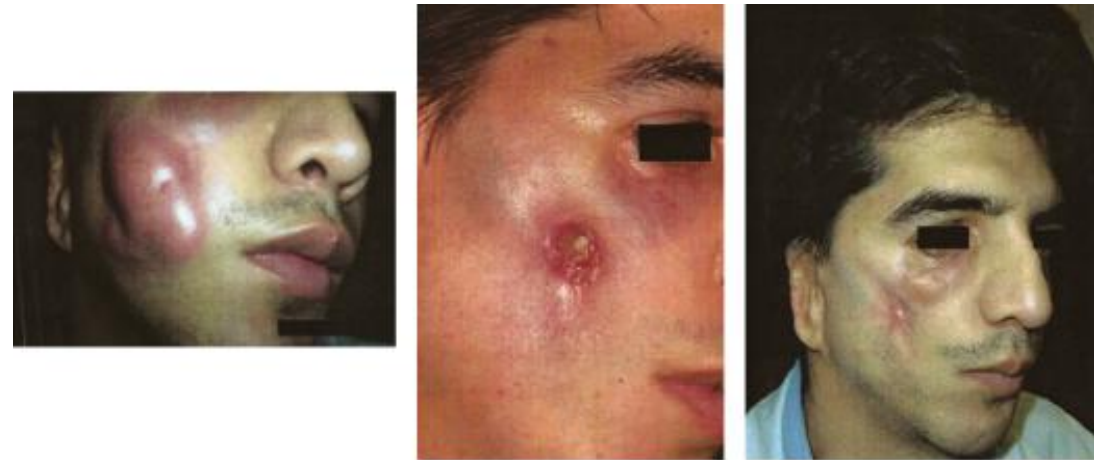

Courtesy of Jorge

Ocampo-Candiani, MD

Fig-7: Abscess and granulomas 4 years later to filler injection and repeat treatment over 6 months [35]
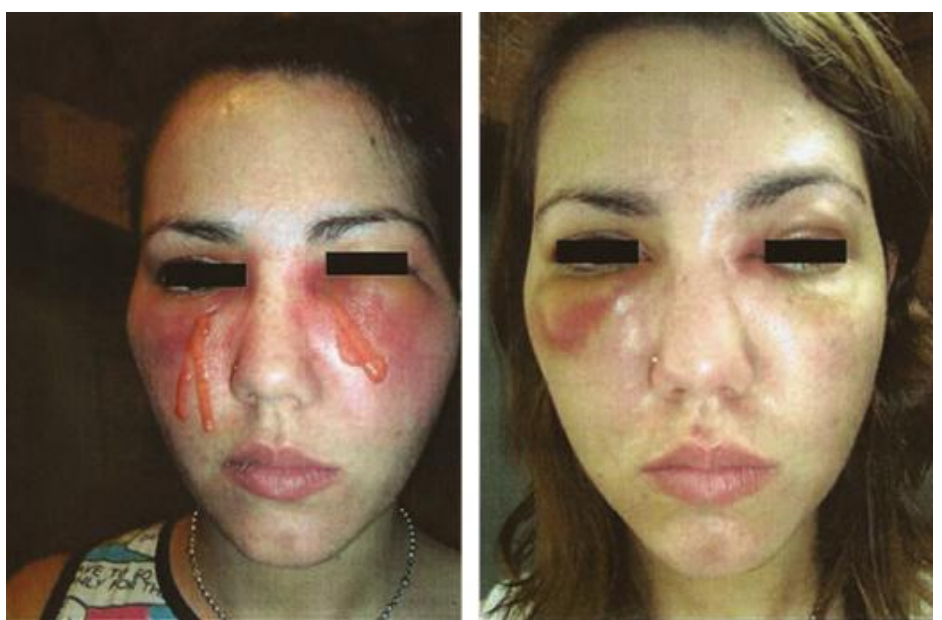

Fig-8: Recurrent secondary infection after filler injection [35] 


\section{Complication and Side Effects}

Plenty amount of people believe that fillers only serve to increase their satisfaction of their appearance regardless of their possible side effect, one of the major complications of filler injection is intravascular and \ or perivascular injections that produce a compression of the vessels leading to tissue necrosis. Nicking of the blood vessels and deposition filler particle are a combined with pain and tissue blanching. Regardless, those symptoms are usually present after filler injection and it cannot be distinguished from intravascular injection. In rare cases intravascular injection in the area proximal to the glabella progress to the central retinal artery by retrograde movement of the particle scattering microemboli inside the retina that leads to complete unilateral vision loss which could be permanent if not recognized and treated instantly [31-33].

Slow and superficial injection could minimize the possibility of these episodes, combined with the back-pressure withdrawal of the syringe that reveals if the tip has perforated the blood vessel. However, the absences of blood does not particularly mean that the vessel was not compromised due to the high viscosity of the filler particles and the small caliber of the needle [24, 34].

\section{REFERENCES}

1. Farage, M. A., Miller, K. W., Elsner, P., \& Maibach, H. I. (2008). Intrinsic and extrinsic factors in skin ageing: a review. International Journal of Cosmetic Science, 30(2), 87-95.

2. Guinot, C., Malvy, D. J. M., Ambroisine, L., Latreille, J., Mauger, E., Tenenhaus, M., ... \& Tschachler, E. (2002). Relative contribution of intrinsic vs extrinsic factors to skin aging as determined by a validated skin age score. Archives of dermatology, 138(11), 1454-1460.

3. Farage, M. A., Miller, K. W., Elsner, P., \& Maibach, H. I. (2008). Functional and physiological characteristics of the aging skin. Aging clinical and experimental research, 20(3), 195-200.

4. McCullough, J. L. (2006). Prevention and Treatment of Skin Aging. Annals of the New York Academy of Sciences Annals of the New York Academy of Sciences. 1067(1):323-331.

5. Kontis, T. C., \& Rivkin, A. (2009). The history of injectable facial fillers. Facial Plastic Surgery, 25(02), 067-072.

6. Jain, M., Bansal, A., Agarwal, D., \& Joshi, M. (2014). Botox in dentistry: The healing side of A poison. J Adv Med Dent Scie, 2(1), 95-99.

7. Barbano, R. (2006). Risks of erasing wrinkles: Buyer beware!. Neurology, 67(10), E17-E18.

8. Meunier, F. A., Schiavo, G., \& Molgó, J. (2002). Botulinum neurotoxins: from paralysis to recovery of functional neuromuscular transmission. Journal of Physiology-Paris, 96(1-2), 105-113.

9. Carruthers, A., \& Carruthers, J. (1998). History of the cosmetic use of botulinum A exotoxin. Dermatologic surgery,24(11), 1168 1171.

10. Lang, A. (2004). History and Uses of BOTOX®(Botulinum Toxin Type A). Professional Case Management,9(2), 109112.

11. Nayyar, P., Kumar, P., Nayyar, P. V., \& Singh, A. (2014). Botox: broadening the horizon of dentistry. Journal of clinical and diagnostic research: JCDR, 8(12), ZE25-9.

12. Jankovic, J., Schwartz, K., \& Donovan, D. T. (1990). Botulinum toxin treatment of cranialcervical dystonia, spasmodic dysphonia, other focal dystonias and hemifacial spasm. Journal of Neurology, Neurosurgery \& Psychiatry, 53(8), 633-639.

13. Berbos, Z. J., \& Lipham, W. J. (2010). Update on botulinum toxin and dermal fillers. Current opinion in ophthalmology, 21(5), 387-395.

14. Cavallini, M., Cirillo, P., Fundarò, S. P., Quartucci, S., Sciuto, C., Sito, G., ... \& Signorini, M. (2014). Safety of botulinum toxin A in aesthetic treatments: a systematic review of clinical studies. Dermatologic Surgery, 40(5), 525536.

15. Vanaman, M., Fabi, S. G., \& Carruthers, J. (2016). Complications in the cosmetic dermatology patient: a review and our experience (part 1). Dermatologic Surgery, 42(1), 1-11.

16. Carruthers, J., \& Carruthers, A. (2005). Adjunctive botulinum toxin type A: fillers and light-based therapies. International clinics, 45(3), 143-151.

ophthalmology

17. Spósito, M. M. (2002). New indications for botulinum toxin type a in cosmetics: mouth and neck. Plastic and reconstructive surgery, 110(2), 601-11.

18. Hexsel, D., \& Dal'forno, T. (2003). Type A botulinum toxin in the upper aspect of the face. Clinics in dermatology, 21(6), 488-497.

19. Nayyar, P., Kumar, P., Nayyar, P. V., \& Singh, A. (2014). Botox: broadening the horizon of dentistry. Journal of clinical and diagnostic research: JCDR, 8(12), ZE25.

20. Ruiz-Rodriguez, R., \& Martin-Gorgojo, A. (2015). Ten mistakes to avoid when injecting botulinum toxin. Actas Dermo-Sifiliográficas (English Edition), 106(6), 458-464.

21. Coleman, K. R., \& Carruthers, J. (2006). Combination therapy with BOTOX ${ }^{\mathrm{TM}}$ and fillers: the new rejuvnation paradigm. Dermatologic therapy, 19(3), 177-188.

22. Lemperle, G., Morhenn, V., \& Charrier, U. (2003). Human histology and persistence of various injectable filler substances for soft tissue 
augmentation. Aesthetic plastic surgery,27(5), 354-366.

23. Kaufman, M. R., Miller, T. A., Huang, C., Roostaien, J., Wasson, K. L., Ashley, R. K., \& Bradley, J. P. (2007). Autologous fat transfer for facial recontouring: is there science behind the art?. Plastic and reconstructive surgery, 119(7), 2287-2296.

24. Murray, C. A., Zloty, D., \& Warshawski, L. (2005). The evolution of soft tissue fillers in clinical practice. Dermatologic clinics, 23(2), 343363.

25. Tal, S., Maresky, H. S., Bryan, T., Ziv, E., Klein, D., Persitz, A., \& Heller, L. (2016). MRI in detecting facial cosmetic injectable fillers. Head \& face medicine, 12(1), 27.

26. Kablik, J., Monheit, G. D., Yu, L., Chang, G., \& Gershkovich, J. (2009). Comparative physical properties of hyaluronic acid dermal fillers. Dermatologic Surgery, 35, 302-312.

27. Lam, S. M., Azizzadeh, B., \& Graivier, M. (2006). Injectable poly-L-lactic acid (Sculptra): technical considerations in soft-tissue contouring. Plastic and reconstructive surgery, $118(3 \mathrm{~S}), 55 \mathrm{~S}-63 \mathrm{~S}$.

28. Eppley, B. L., \& Dadvand, B. (2006). Injectable soft-tissue fillers: clinical overview. Plastic and reconstructive surgery, 118(4), 98e-106e.

29. Buck II, D. W., Alam, M., \& Kim, J. Y. (2009). Injectable fillers for facial rejuvenation: a review. Journal of Plastic, Reconstructive \& Aesthetic Surgery, 62(1), 11-18.

30. Hohaus, K., Bley, B., Köstler, E., Schönlebe, J., \& Wollina, U. (2003). Mineral oil granuloma of the penis. Journal of the European Academy of Dermatology and Venereology, 17(5), 585-587.

31. Beleznay, K., Carruthers, J. D., Humphrey, S., \& Jones, D. (2015). Avoiding and treating blindness from fillers: a review of the world literature. Dermatologic Surgery,41(10), 1097 1117.

32. Minkis, K., Whittington, A., \& Alam, M. (2016). Dermatologic surgery emergencies: complications caused by occlusion and blood pressure. Journal of the American Academy of Dermatology, 75(2), 243-262.

33. Matarasso, S. L. (2015). Pan-facial volumization: the new face of youth. Dermatologic Surgery, 41(12), 1370-1371.

34. Carey, W., \& Weinkle, S. (2015). Retraction of the plunger on a syringe of hyaluronic acid before injection: are we safe? Dermatologic Surgery, 41, S340-S346.

35. Monheit, G. D., \& Rohrich, R. J. (2009). The nature of long-term fillers and the risk of complications. Dermatologic surgery, 35, 15981604 . 